\title{
REVIEW \\ Secretory granule behaviour adjacent to the plasma membrane before and during exocytosis: total internal reflection fluorescence microscopy studies
}

\author{
R. W. Holz' and D. Axelrod ${ }^{2}$ \\ I Department of Pharmacology, University of Michigan, Ann Arbor, MI USA \\ 2 Departments of Physics and Biophysics, University of Michigan, Ann Arbor, MI, USA
}

Received 2 May 2007, accepted 27 August 2007 Correspondence: R. W. Holz, 230I MSRB III, Department of Pharmacology, University of Michigan Medical School, Ann Arbor, MI 48I09-5632, USA. E-mail: holz@umich.edu

\begin{abstract}
Our current notions of different granule pools, granule interaction with the plasma membrane, and ultimately granule and plasma membrane soluble $\mathrm{N}$-ethylmaleimide-sensitive-factor attachement protein (SNARE) interactions, result largely from inferences based upon biochemical alterations of secretion kinetics. Another view of events comes from studies using total internal reflection fluorescence microscopy (TIRFM) to investigate granule behaviour immediately adjacent to the plasma membrane. The motions of secretory (chromaffin) granules in bovine chromaffin cells visualized by TIRFM are highly restricted, as if granules are caged or tethered. These small motions are regulated by ATP and $\mathrm{Ca}^{2+}$, two factors that increase priming of the secretory response. There is no evidence that granules decrease their motion immediately before secretion. To the contrary, there is a tendency for granules to increase their motions and travel within a few hundred milliseconds of fusion. Hence, the notion of a long-lived docked state as a prelude to fusion does not encompass the physical reality of molecular scale motions, multiple tethering states and significant travel immediately preceding the exocytotic event. Increased travel may increase the probability of granules interacting productively with the plasma membrane constituents, thereby, increasing the probability of fusion.

Keywords chromaffin cells, exocytosis, secretory granule, SNARE proteins, total internal reflection fluorescence microscopy.
\end{abstract}

Virtually all models of exocytosis envision granule movement to the plasma membrane and a plasma membrane docking step. The precise nature of these events has been surmised but not directly investigated. 'Morphological' docking has been defined by static electron microscopic images (Nakata \& Hirokawa 1992, Vitale et al. 1995, Steyer et al. 1997). Inferences concerning the dynamics of events immediately before fusion are based upon the kinetics of secretion. In these experiments granule pools are defined by the rates at which granules fuse with the plasma membrane after a $\mathrm{Ca}^{2+}$ stimulus and the manner in which the kinetics are altered by biochemical manipulations. Another view of granule behaviour comes from quantitative studies of granule motion using wide field, confocal and especially total internal reflection fluorescence microscopy (TIRFM) of fluorescent-tagged secretory granules. The latter technique selectively illuminates the aqueous phase immediately adjacent to a glass interface with an exponentially decaying excitation (the evanescent field, decay constant 50-100 nm) (Axelrod 1981, 2003). A distance into the cell extending less than a granule diameter is selectively visualized. Motions of granules labelled with green fluorescent protein (GFP)-tagged lumenal cargo or granule membrane protein can be determined with resolution of $\sim 10 \mathrm{~nm}$. 
Motions perpendicular to the glass interface ( $z$ motions) are calculated from changes in fluorescence intensity, whereas granule motions parallel to the glass interface ( $R$ motions) are determined by interpolated centre of intensity measurements (Johns et al. 2001, Allersma et al. 2004). A common finding in TIRFM studies in chromaffin cells is that most $(>98 \%)$ of the granules adjacent to the plasma membrane are highly restricted in their motion (Steyer et al. 1997, Oheim et al. 1998, Han et al. 1999, Johns et al. 2001, Ohara-Imaizumi et al. 2002) as if tethered or caged. The size of the motions, tens of nanometres, is the size of large proteins and of individual steps sizes of molecular motors (5-10 nm for myosin II and $37 \mathrm{~nm}$ for myosin Va) (Mehta et al. 1999, Murphy et al. 2001, Veigel et al. 2003, Yildiz et al. 2003).

\section{Techniques}

In the experiments described below, we used objectivebased TIRFM, which was obtained by focusing an Argon ion laser $(488 \mathrm{~nm})$ on the periphery of the back focal plane of a $100 \times 1.65 \mathrm{NA}$, oil immersion objective (Olympus, Center Valley, PA, USA). The laser beam was incident on the coverslip at $58-64^{\circ}$ to the optical axis, resulting in a $\sim 55 \mathrm{~nm}$ decay constant of the evanescent field. Digital images were captured on a cooled CCD camera. Images were acquired at $10 \mathrm{~Hz}$ with exposure times of 20-50 ms.

A major issue for interpretation of the experiments is the need for demanding image analysis. Granules were identified and tracked through a time-sequence stack of images using software written in interactive data language (ITT Visual Information Solutions, Boulder, $\mathrm{CO}, \mathrm{USA})$. The procedures permitted the analysis of vast amounts of information. Granules undergoing exocytosis were visually identified. From the stack of images, a data set was generated containing $x$ and $y$ coordinates, granule intensity and local background for each granule in each frame. The $x$ and $y$ coordinates were determined from band-pass-filtered images. Positions were calculated from the peaks of inverted parabolas determined by the intensities of the brightest pixel and each immediately adjacent pixel in the diagonals. Changes in position perpendicular to the glass interface ( $Z$ direction) were calculated from changes in granule intensity resulting from the exponential decay of the excitation. Total granule intensity was determined in unfiltered images from the average pixel intensity within a circular region (600 $\mathrm{nm}$ diameter, 81 pixel area) around the granule centre after the local background was subtracted. The local background was the average intensity of a ring of 32 pixels just outside the circle. The data set was then analysed to track granules, calculate inter-frame motions and determine measures of granule travel in the $x y$ plane.
Monolayers of bovine chromaffin cells were transfected with a plasmid encoding atrial natriuretic peptide (ANP)-GFP, a marker of the secretory granule lumen or vesicle associated membrane protein (VAMP)-GFP, a marker of the secretory granule membrane. Cells were transfected using calcium phosphate precipitation within $16 \mathrm{~h}$ of dissociation. Experiments were performed 4-7 days later, which is sufficient time for labelled granules to mature and attain the cellular distribution and secretory characteristics of endogenous secretory granules. These characteristics are important because newly synthesized granules have different trafficking and secretory characteristics than the majority of endogenous granules that are responsible for secretion in these highly, differentiated, non-dividing cells (Duncan et al. 2003).

\section{Granule motions are regulated}

Granules undergo priming steps before secretion that are regulated by ATP and calcium (Holz et al. 1989, Bittner \& Holz 1992, Rüden \& Neher 1993). These co-factors also affect granule motion (Allersma et al. 2006). Removal of ATP in permeabilized cells caused granule motion to decrease. Motions of individual granules were tracked during incubation with ATP and during a following change to a solution either with or without ATP. Average granule motions in the $X Y$ and $Z$ directions were unchanged in the continuing presence of ATP but decreased by $\sim 20 \%$ within 1 min of ATP removal. A larger effect of ATP removal was observed when the motions of a subpopulation of granules that were especially slow moving in the XY plane were analysed. Motions of these granules increased $38 \%$ in the continuing presence of ATP whereas upon ATP removal, motions were further decreased by $13 \%$. Hence, a major effect of ATP is to increase the motion of slow moving granules. Removal of ATP is associated with a loss of plasma membrane PtdIns-4,5- $\mathrm{P}_{2}$ (Eberhard et al. 1990, Holz et al. 2000) and a loss of cortical actin (Bittner \& Holz 2005). The interplay between changes in the environment of granules visualized by TIRFM and granule motions is not understood but could involve molecular motors such as myosin II and myosinVa. Despite numerous investigations over the years, the roles of actin in late stages of the secretory pathway are poorly understood. TIRFM studies indicate that cortical actin does not play a major role in restricting granule motion (Lang et al. 2000, Allersma et al. 2006).

Nicotinic stimulation causes a small calciumdependent increase in granule motion (Allersma et al. 2006). The analysis of the motion of 330 non-fusing granules revealed a $17 \%$ increase in the median motion in the $X Y$ and $Z$ directions $(P<0.001)$. The effect of $\mathrm{Ca}^{2+}$ in increasing granule motion has been observed in other tissues. For example, in the Drosophila neuro- 
muscular junction $\mathrm{Ca}^{2+}$, calmodulin and calmodulin kinase II have been implicated in increased motion (Shakiryanova et al. 2005, 2007).

Of major interest is the motion of the subpopulation of granules about to undergo exocytosis. Surprisingly, these granules undergo relatively large increases in motion and travel within several hundreds of milliseconds of fusion, as described below. This effect is not observed for neighbouring, non-fusing granules.

\section{Visualization of exocytosis with VAMP-GFP}

Secretory granules labelled with the v-SNARE, VAMPGFP (GFP luminal), showed distinct signatures upon exocytosis when viewed by TIRFM (Allersma et al. 2004). In approximately $90 \%$ of fusion events, we observed a large increase in fluorescence intensity coupled with a transition from a small punctate appearance to a larger, spreading cloud with free diffusion of the VAMP-GFP into the plasma membrane (Fig. 1). Quantitation indicates that these events reflect two steps in the fusion process: (1) initially, a fused and spherical granule resulting in an approximately twofold increase in fluorescence due to the increase in lumenal $\mathrm{pH}$, and (2) subsequent granule flattening into the plasma membrane and/or free diffusion of VAMP-GFP through the fusion junction into the plasma membrane. Fluorescence spreads and further brightens approximately fivefold as VAMP-GFP is brought closer to the glass interface (Allersma et al. 2004). The distinctive fluorescence changes upon of fusion obtained with VAMP-GFP-labelled granules permitted timing of the beginning of fusion events to within $0.1-0.2 \mathrm{~s}$.

\section{Granules can move tens to hundreds of nanometres within $100 \mathrm{~ms}$ of fusion}

Most of the granules that undergo secretion in chromaffin cells are present in the evanescent field for tens of seconds to many minutes. Motions both in the $X Y$ plane and $Z$ direction increase within the last seconds before fusion (Allersma et al. 2006, Degtyar et al. 2007) with an average twofold increased in the last $100 \mathrm{~ms}$ before fusion. There is considerable variability in the absolute magnitude of the motions. However, almost all of the granules had motions in the $X Y$ plane within $100 \mathrm{~ms}$ of fusion that was well above instrumental noise (Allersma et al. 2006). The motions ranged from $<10$ to $200 \mathrm{~nm}$.

\section{The travel of granules destined to fuse is increased immediately before exocytosis}

The above studies focused on the average motions during $100 \mathrm{~ms}$ intervals. Important aspects of granule dynamics are suggested by inspection of granule paths parallel to the glass interface over many seconds. In Figure 2, a granule is followed for $5 \mathrm{~s}$ before stimulation (black track beginning at ' $\mathrm{O}$ ') and then for $9 \mathrm{~s}$ during nicotinic stimulation (red track) until it fuses with the plasma membrane at ' $\mathrm{X}$ '. The granule moves less than its diameter during the entire sequence. The high spatial resolution measurements suggest that the granule increases its travel upon stimulation. Just before fusion the granule moves to an area it has not visited previously.

Analysis of 72 tracks of granules that are destined to fuse confirms these impressions (Degtyar et al. 2007). Granules extend their travel during stimulation and often move to areas not previously visited in the last few hundred milliseconds before fusion. This was most evident for granules that fused after $8 \mathrm{~s}$ of nicotinic stimulation. Fifty-eight per cent of these fusion events occurred in granules that had suddenly moved to an area that they had rarely or never visited before $(0-2$ visits). In contrast, during the rest of the track ( 29 positions), only $12 \%$ of the time did granules move to a position which had been visited twice or less. When the motions of the same granules were analysed in the

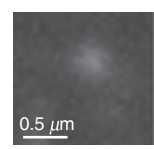

$-0.2$

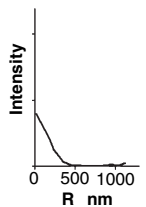

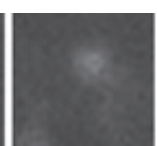

0.0

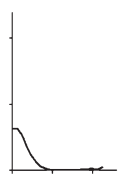

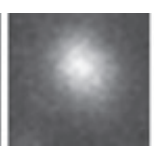

0.1



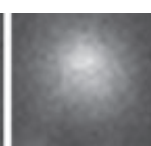

0.2

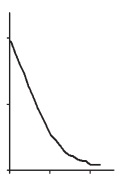

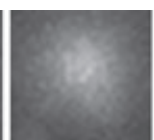

0.3

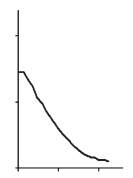

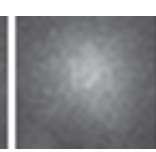

0.4

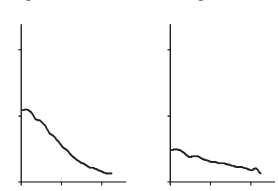

Figure I An intensity burst characterizes the fusion of an individual VAMP-GFP-labelled granule with the plasma membrane. Successive frames show the fusion of a VAMP-GFP-containing granule and the subsequent spread of the VAMP-GFP in the plasma membrane in TIRFM. The frame just prior to fusion is $t=0.0 \mathrm{~s}$. Below each image is the VAMP-GFP intensity (with background subtracted) averaged as a function of radial distance $r$ away from the granule centre. Peak intensity is in the centre of the intensity profile. The fluorescence almost completely disappeared after $1 \mathrm{~s}$ (from Allersma et al. 2004). 


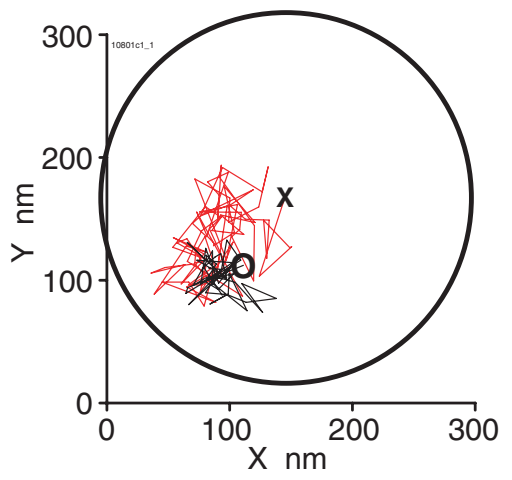

Figure 2 Track of a chromaffin granule before and during stimulation until fusion. The granule was followed for $5 \mathrm{~s}$ before stimulation (black path) and for $9 \mathrm{~s}$ during stimulation with DMPP (red path) until fusion (marked with ' $\mathrm{X}$ '). The large black circle represents a $300-\mathrm{nm}$ granule centred on the last position before fusion. ' $\mathrm{O}$ ' indicates the beginning of the track.

same way for 30 frames before nicotinic stimulation, there was no difference between the last position and the 29 previous positions in the tendency of granules to visit new regions. The frequency of $0-2$ previous visits to the same area for the last position was only $17 \%$. The tendency to move to new areas was acquired within $0.7 \mathrm{~s}$ of fusion. It was not observed for non-fusing granules analysed at the same time as their fusing neighbours.

These observations of granule motion before exocytosis contrast with the common assumption that granules that are morphologically close to the plasma membrane (within a granule diameter) are stably interacting with the membrane and that this bound state is required for priming and subsequent exocytosis. Granules with very small motions $(<10 \mathrm{~nm})$ may indeed be interacting with proteins involved in the fusion reaction. However, those with large motions (>50 nm) probably engage the fusion machinery only within the last $100 \mathrm{~ms}$.

There are at least two explanations for the increased motion and travel of granules before exocytosis. One is statistical. Some granules are favourably positioned at the time of stimulation to interact with key proteins or lipids, thus allowing fusion to occur relatively quickly with little travel. These granules may be part of the rapidly releasable pool detected after flash photolysis of caged $\mathrm{Ca}^{2+}$ (Rettig \& Neher 2002). However, many granules are not in a favourable location for fusion. For such granules, sampling the plasma membrane in new territory rather than in domains that the granule had already visited unproductively increases the probability of subsequent fusion. Indeed, the greater tendency of late fusing granules to travel to new areas in the last few hundred milliseconds before fusion supports this notion. The increased travel could reflect the action of molecular motors or sudden granule untethering.

Alternatively, the increased motion may be part of the fusion mechanism itself. For example, spatially asymmetrical, successive zippering of multiple SNARE complexes (10 nm motions; Liu et al. 2006) may increase motion of the granule along the plasma membrane just before fusion.

In summary, it is evident from our work (Johns et al. 2001, Allersma et al. 2004, 2006) and the work of others (Steyer et al. 1997, Oheim et al. 1998, Lang et al. 2000, Huet et al. 2006, Toonen et al. 2006, Tsuboi \& Fukuda 2006, Nofal et al. 2007) that there are different states of granule tethering adjacent to the plasma membrane. High resolution measurements of granule motion indicate that the highly restricted motion is regulated. Quantitative measures of granule motion and travel of fusing granules during nicotinic stimulation indicate that the notion of a long-lived docked state as a prelude to fusion does not encompass the physical reality of molecular scale motions, multiple tethering states and significant travel immediately preceding the exocytotic event. To the contrary, our recent analyses suggest that granules with greater travel and the ability to interact with more regions along the plasma membrane can be favoured to undergo fusion.

\section{Conflict of interest}

There is no conflict of interest.

This work was funded by National Institutes of Health grant RO1-DK50127 (to R.W.H.), grant R01-NS38129 (to R.W.H. and D.A.) and a Michigan Economic Development Corporation and Michigan Life Sciences Corridor Grant (to R.W.H.).

\section{References}

Allersma, M.W., Wang, L., Axelrod, D. \& Holz, R.W. 2004. Visualization of regulated exocytosis with a granule-membrane probe using total internal reflection microscopy. Mol Biol Cell 15, 4658-4668.

Allersma, M.W., Bittner, M.A., Axelrod, D. \& Holz, R.W. 2006. Motion matters: secretory granule motion adjacent to the plasma membrane and exocytosis. Mol Biol Cell 17, 2424-2438.

Axelrod, D. 1981. Cell-substrate contacts illuminated by total internal reflection fluorescence. J Cell Biol 89, 141-145.

Axelrod, D. 2003. Total internal reflection fluorescence microscopy in cell biology. Methods Enzymol 361, 1-33.

Bittner, M.A. \& Holz, R.W. 1992. Kinetic analysis of secretion from permeabilized adrenal chromaffin cells reveals distinct components. J Biol Chem 267, 16219-16225.

Bittner, M.A. \& Holz, R.W. 2005. Phosphatidylinositol4,5-bisphosphate:actin dynamics and the regulation of ATP- 
dependent and independent secretion. Mol Pharmacol 67, 1089-1098.

Degtyar, V.E., Allersma, M.W., Axelrod, D. \& Holz, R.W. 2007. Increased motion and travel, rather than stable docking, characterize the last moments before secretory granule fusion. Proc Natl Acad Sci USA 104, 15929_ 15934.

Duncan, R.R., Greaves, J., Wiegand, U.K., Matskevich, I., Bodammer, G., Apps, D.K., Shipston, M.J. \& Chow, R.H. 2003. Functional and spatial segregation of secretory vesicle pools according to vesicle age. Nature 422, 176-180.

Eberhard, D.A., Cooper, C.L., Low, M.G. \& Holz, R.W. 1990. Evidence that the inositol phopholipids are necessary for exocytosis: loss of inositol phospholipids and inhibition of secretion in permeabilized cells caused by a bacterial phospholipase $\mathrm{C}$ and removal of ATP. Biochem J 268, 15-25.

Han, W., Ng, Y.K., Axelrod, D. \& Levitan, E.S. 1999. Neuropeptide release by efficient recruitment of diffusing cytoplasmic secretory vesicles. Proc Natl Acad Sci USA 96, 14577-14582.

Holz, R.W., Bittner, M.A., Peppers, S.C., Senter, R.A. \& Eberhard, D.A. 1989. MgATP-independent and MgATPdependent exocytosis. Evidence that MgATP primes adrenal chromaffin cells to undergo exocytosis. J Biol Chem 264, 5412-5419.

Holz, R.W., Hlubek, M.D., Sorensen, S.D., Fisher, S.K., Balla, T., Ozaki, S., Prestwich, G.D., Stuenkel, E.L. \& Bittner, M.A. 2000. A pleckstrin homology domain specific for PtdIns-4-5- $\mathrm{P}_{2}$ and fused to green fluorescent protein identifies plasma membrane PtdIns-4-5- $\mathrm{P}_{2}$ as being important in exocytosis. J Biol Chem 275, 17878-17885.

Huet, S., Karatekin, E., Tran, V.S., Fanget, I., Cribier, S. \& Henry, J.P. 2006. Analysis of transient behavior in complex trajectories: application to secretory vesicle dynamics. Biophys J 91, 3542-3559.

Johns, L.M., Levitan, E.S., Shelden, E.S., Holz, R.W. \& Axelrod, D. 2001. Restriction of secretory granule motion near the plasma membrane of chromaffin cells. J Cell Biol 153, 177-190.

Lang, T., Wacker, I., Wunderlich, I., Rohrbach, A., Giese, G., Soldati, T. \& Almers, W. 2000. Role of actin cortex in the subplasmalemmal transport of secretory granules in PC-12 cells. Biophys J 78, 2863-2877.

Liu, W., Montana, V., Bai, J., Chapman, E.R., Mohideen, U. \& Parpura, V. 2006. Single molecule mechanical probing of the SNARE protein interactions. Biophys $J$ 91, 744758.

Mehta, A.D., Rock, R.S., Rief, M., Spudich, J.A., Mooseker, M.S. \& Cheney, R.E. 1999. Myosin-V is a processive actinbased motor. Nature 400, 590-593.

Murphy, C.T., Rock, R.S. \& Spudich, J.A. 2001. A myosin II mutation uncouples ATPase activity from motility and shortens step size. Nat Cell Biol 3, 311-315.
Nakata, T. \& Hirokawa, N. 1992. Organization of cortical cytoskeleton of cultured chromaffin cells and involvement in secretion as revealed by quick-freeze, deep- etching, and double-label immunoelectron microscopy. J Neurosci 12, 2186-2197.

Nofal, S., Becherer, U., Hof, D., Matti, U. \& Rettig, J. 2007. Primed vesicles can be distinguished from docked vesicles by analyzing their mobility. J Neurosci 27, 1386-1395.

Ohara-Imaizumi, M., Nakamichi, Y., Tanaka, T., Ishida, H. \& Nagamatsu, S. 2002. Imaging exocytosis of single insulin secretory granules with evanescent wave microscopy. Distinct behavior of granule motion in biphasic insulin release. J Biol Chem 277, 3805-3808.

Oheim, M., Loerke, D., Stuhmer, W. \& Chow, R.H. 1998. The last few milliseconds in the life of a secretory granule. Docking, dynamics and fusion visualized by total internal reflection fluorescence microscopy (TIRFM). Eur Biophysics J 27, 83-98.

Rettig, J. \& Neher, E. 2002. Emerging roles of presynaptic proteins in Ca++-triggered exocytosis. Science 298, 781.

Rüden, v.L. \& Neher, E. 1993. A Ca-dependent early step in the release of catecholamines from adrenal chromaffin cells. Science 262, 1061-1065.

Shakiryanova, D., Tully, A., Hewes, R.S., Deitcher, D.L. \& Levitan, E.S. 2005. Activity-dependent liberation of synaptic neuropeptide vesicles. Nat Neurosci 8, 173-178.

Shakiryanova, D., Klose, M.K., Zhou, Y., Gu, T., Deitcher, D.L., Atwood, H.L., Hewes, R.S. \& Levitan, E.S. 2007. Presynaptic ryanodine receptor-activated calmodulin kinase II increases vesicle mobility and potentiates neuropeptide release. J Neurosci 27, 7799-7806.

Steyer, J.A., Horstman, H. \& Almers, W. 1997. Transport, docking and exocytosis of single secretory granules in live chromaffin cells. Nature 388, 474-478.

Toonen, R.F., Kochubey, O., de Wit, H., Gulyas-Kovacs, A., Konijnenburg, B., Sorensen, J.B., Klingauf, J. \& Verhage, M. 2006. Dissecting docking and tethering of secretory vesicles at the target membrane. EMBO J 25, 3725-3737.

Tsuboi, T. \& Fukuda, M. 2006. The Slp4-a linker domain controls exocytosis through interaction with Munc18-1-Syntaxin-1a complex. Mol Biol Cell 17, 21012112.

Veigel, C., Molloy, J.E., Schmitz, S. \& Kendrick-Jones, J. 2003. Load-dependent kinetics of force production by smooth muscle myosin measured with optical tweezers. Nat Cell Biol 5, 980-986.

Vitale, M.L., Seward, E.P. \& Trifaro, J.-M. 1995. Chromaffin cell cortical actin network dynamics control the size of the release-ready vesicle pool and the initial rate of exocytosis. Neuron 14, 353-363.

Yildiz, A., Forkey, J.N., McKinney, S.A., Ha, T., Goldman, Y.E. \& Selvin, P.R. 2003. Myosin V walks hand-over-hand: single fluorophore imaging with $1.5 \mathrm{~nm}$ localization. Science 300, 2061-2065. 